\title{
Can zero-hour cortical biopsy predict early graft outcomes after living donor renal transplantation?
}

Ranjeet Singh Rathore, Nisarg Mehta, Sony Bhaskar Mehta, Manas Babu, Devesh Bansal, Biju S. Pillai, Mohan P. Sam, H. Krishnamoorthy

Department of Urology, Lourdes Hospital, Kochi, India

Cite as: Can Urol Assoc J 2017; Epub ahead of print. http://dx.doi.org/10.5489/cuaj.4506

Published online November 1, 2017

\section{Abstract}

Introduction: The aim of this study was to identify relevance of subclinical pathological findings in the kidneys of living donors and correlate these with early graft renal function. Methods: This was a prospective study on 84 living donor kidney transplant recipients over a period of two years. In all the donors, cortical wedge biopsy was taken and sent for assessment of glomerular, mesangial, and tubule status. The graft function of patients with normal histology was compared with those of abnormal histological findings at one, three, and six months, and one year post-surgery.

Results: Most abnormal histological findings were of mild degree. Glomerulosclerosis (GS, $25 \%$ ), interstitial fibrosis (13\%), acute tubular necrosis (ATN 5\%), and focal tubal atrophy (5\%) were the commonly observed pathological findings in zero-hour biopsies. Only those donors who had histological changes of interstitial fibrosis and ATN showed progressive deterioration of renal function at one month, three months, six months, and one year posttransplantation. In donors with other histological changes, no significant effect on graft function was observed.

Conclusion: Zero-hour cortical biopsy gave us an idea of the general status of the donor kidney and presence or absence of subclinical pathological lesions. A mild degree of subclinical and pathological findings on zero-hour biopsy did not affect early graft renal function in living donor kidney transplantation. Zero-hour cortical biopsy could also help in discriminating donor-derived lesions from de novo alterations in the kidney that could happen subsequently. 


\section{Introduction}

Chronic kidney disease (CKD) is a common and rapidly increasing global public health problem, both in developed and developing countries. Kidney transplantation remains the treatment of choice for ESRD as it leads to longer survival and superior quality of life ${ }^{\mathbf{1}}$ it is estimated that in India, 3500 patients undergo renal transplantation annually ${ }^{2}$ The graft recipients, their relatives and transplantation team are always eager to know how the grafted kidney will behave and how long will it survive. Several attempts had been made -to predict the early graft out come by assessing the histologic changes in "zero hour" graft biopsy; however, the issue still remains controversial ${ }^{3,4,5,6}$ The post-revascularisation "zero hour” biopsy of renal allograft could provide useful information on subclinical renal lesions present in the healthy donors and the pathological changes which are being transmitted from the donor to recipient via grafted kidney. It might also act as a baseline biopsy for comparing morphology with subsequent graft biopsies. Lesions like Intimal fibrosis, Glomerulonephritis, Tubular Atrophy and Interstitial Fibrosis etc. may either pre-exist or may be of new onset. Majority of existing studies reported on "zero-hour" biopsy in predicting early and late graft outcome in cadaveric donors. Information on post-revascularisation renal allograft biopsies in live related donors is limited.

\section{Methods}

After getting Institutional Ethics Committee Clearance, a prospective study was conducted from March 2014 to December 2016. Informed consent from both the donors and recipients undergoing live donor renal transplantation were obtained.

A total of 84 patients (43 males and 41 females) of the age group 13-63 years, who underwent open donor nephrectomy and renal transplantation at the institution during the above mentioned period, were enrolled in the study. Preoperative donor evaluation was done to evaluate medical, surgical, and psychosocial suitability for living donation, prior to selection of patients for transplantation.

All the recipients included in the study were given same standard immunosuppressive therapy regime consisting of Tab Tacrolimus $3 \mathrm{mg}$ (once a day: OD), Tab Mycophenolate Mofetil $500 \mathrm{mg}$ OD and injection Methylprednisolone $500 \mathrm{mg}$ intravenously daily starting five days prior to the transplantation. Injection Basiliximab $20 \mathrm{mg}$ intravenously in $100 \mathrm{ml}$ normal saline stat was given to all the recipients if the donor was unrelated. Injection Methyl Prednisolone was replaced by Tab prednisolone $30 \mathrm{mg}$ OD from day 3rd post operatively. Cortical wedge biopsy of the size $1 \mathrm{x} 0.5 \mathrm{x} 0.3 \mathrm{~cm}^{3}$ of the transplanted kidney was taken immediately after revascularization after completing the vascular anastomosis. The main idea behind taking Wedge biopsy was to ensure adequate tissue (at least 20 glomeruli per core) for histopathological examination. In all the 84 cases, the wedge biopsy was taken by single transplant surgeon. Specimens were fixed immediately in $10 \%$ buffered formalin and embedded in paraffin. Three micron thick serial sections were cut and stained with H\&E, Periodic acid Schiff's, Masson's Trichrome, and Periodic Schiff Silver Methylamine stain. A detailed histological examination of post revascularisation graft biopsies was performed and looked for following:

1. Glomerular Status, number of glomeruli per core, and any evidence of Glomerular Sclerosis 
2. Mesangial status

3. Tubule status and number of tubules per core

In all transplant recipients, graft function was assessed by serum creatinine post transplantation. All patients had follow-up visit in their 1st, 3rd, 6th month and 1 year of operation to determine if there is any "allograft dysfunction" defined as serum $\mathrm{Cr}>15 \%$ of the baseline value or lack of response to increasing steroid dose. All the patients who developed delayed graft function had to be supported by haemodialysis post transplantation until these, renal functions normalized within one month. All those patients who needed follow up biopsies post transplantation were done percutaneously under CT guidance and by single expert radiologist.

\section{Statistical analysis}

"Pearsons Correlation" coefficient test was used for correlating serum creatinine values of patients with normal donor histology with serum creatinine values of patients who had abnormal donor histology at 1month, 3 months, and 6 months and at 1 year post transplantation.

\section{Results}

Out of 84 donors, 43 subjects were males and 41 were females. The mean age of the patients was $41 \pm 9.5$ years.

44 patients out of 84 patients (52\%) had normal histology of the donor kidney. Only 40 patients (48\%) had abnormal histological changes which include Glomerulosclerosis (GS: 25\%), Interstitial fibrosis (13\%), Acute Tubular Necrosis (ATN: 5\%) and Focal tubal atrophy (FTA: 5\%) (Table 1).

The effects of various histological changes on graft function at 1 month are given in Table 1. Only recipients with grafts having Interstitial Fibrosis and Acute Tubular Necrosis showed progressive deterioration of renal function at one month. Out of 4 patients who had ATN on biopsy, 2 developed acute rejection and 2 had delayed graft function post transplantation. Four patients of interstitial fibrosis group also had delayed graft function. Other histological changes in the graft had no effect on graft function.

Both the patients, who had acute rejection died within 3months post transplantation due to systemic infections. All the patients who had delayed graft function required haemodialysis post surgery for optimization of kidney function.

Table 2 shows Serum creatinine values in patients with normal histology and also of patients with various coexisting histological changes in donor kidneys preoperatively and at 1 month, 3 months, 6 months, and 1 year post operatively. Only Interstitial Fibrosis and ATN showed progressive increase in serum creatinine values at one month and 1 year. In cases of both the histological changes, rise in serum creatinine started at 1month post operatively and continued to rise till one year of follow up. On correlating serum creatinine values of these patients with those patients who had normal histology (Table 3), both Interstitial Fibrosis and ATN showed strong positive correlation. ( $\mathrm{p}=0.0003$ and $\mathrm{p}=0.0009$ at 1 year post surgery). Patients with other histological changes in donor biopsy like Glomerulosclerosis and Focal Tubal Atrophy also showed marginal rise in serum creatinine obtained post operatively which was statistically insignificant.( $\mathrm{p}=0.0581$ and $\mathrm{p}=0.083$ at 1 year). 


\section{Discussion}

It is well known that, there are various donor and recipient factors which determine the function and survival of the graft after live donor renal transplantation. Donor related factors including age, organ size and quality, pre operative GFR, and co morbid conditions like diabetes, hypertension and smoking have been reported to have significant bearing on graft function post transplantation. However the role of 'Zero hour" cortical biopsy taken from donor kidney post transplantation on graft function post operatively has not been widely studied.The cortical wedge biopsy was taken as it provides adequate quantity of tissue(atleast 20 glomeruli per core) needed for histopathological examination. ${ }^{7}$ In our study "Zero hour" cortical biopsy showed that Glomerulosclerosis (25\%) was the most common histological abnormality followed by, Acute Tubular necrosis (5\%), Interstitial Fibrosis (13\%) and Focal Tubal Atrophy (5\%) which is almost similar to the histological findings noted by Lee AL at $\mathrm{al}^{.8}$

High grade of Glomerulosclerosis has been reported to be a good predictor of early graft dysfunction ${ }^{8}$ However in our study, the grade of Glomerulosclerosis was not taken into account due difference in the number of glomeruli per core seen in different biopsy specimens. However, the presence of Interstitial Fibrosis correlated well with worst results in long-term graft survival (chi-square $\mathrm{p}=0.029$; $\mathrm{RR}=2.23$; 95\% CI, 1.07-4.64). Similar results had been reported by Lopes et al ${ }^{9}$ who found a positive correlation between IF and serum creatinine at 3 and 6 months but no correlation with TA and GS. Interestingly same authors assumed that none of the histological variables and scores provided perfect predictions and so they cautioned that results should be interpreted in the context of all available information on donor-recipients. 8,13

Table 4 shows comparison of our study with the standard published literature in terms of types of histological changes seen, overall survival, number of deaths, allograft dysfunction; our findings were matching with majority of the studies.

It has been reported that Implantation Biopsy Score (IBS) 4-6 could determine an increased risk of early graft loss, especially primary nonfunction ${ }^{11}$

Higher IBS grades predict lower graft function until the $3^{\text {rd }}$ postoperative year; but in this cohort we could not assess IBS because of shorter follow up period.

Nowadays, preoperative biopsies could be considered as a graft survival prediction tool, with high specificity (despite a low sensitivity). Since the advent of cyclosporine era of immunosuppression, we have dramatically reduced the impact of allograft acute rejections, remaining with late losses due to chronic allograft dysfunction ${ }^{11}$

\section{Limitations of the study}

The sample size of the study was 84 , which seems to be inadequate and needs further study with larger number of transplant patients so as to extrapolate the required outcomes representative of population at large. The effects of pre operative eGFR and its correlation to donor's age and comorbidities which could have effected graft function post transplantation were not studied. Follow up of our patients was for short period and hence long term effect on graft function could not be assessed.

\section{Conclusions}


"Zero hour" cortical biopsy gave information about the general status of the donor kidney and presence or absence of subclinical pathological lesions. However it was observed that mild degree of subclinical, pathologic findings on "zero hour” biopsy did not affect early graft renal function in living-donor kidney transplantation. Interstitial Fibrosis and Acute Tubular Necrosis were the only histological abnormalities associated with significant effect on allograft dysfunction. 


\section{References}

1. Garcia GG, Harden P, Chapman J. World Kidney Day Steering Committee. The global role of kidney transplantation. Lancet 2012; 379: 36-8.

2. Agarwal SK, Srivastava RK. Chronic kidney disease in India: Challenges and solutions. Nephron Clin Tract 2009; 111: 197-203.

3. Cerilli J, Holliday JE, Wilson CB et al. Clinical significance of the 1-hour biopsy in renal transplantation. Transplantation 1978; 26: 91-93.

4. Curschellas E, Landmann J, Durig M et al. Morphologic findings in "zero-hour" biopsies of renal transplants. Clin Nephrol 1991; 36: 215-22.

5. Szanya J, Szakaly P, Magyarlaki T et al. Predictive morphological findings in "zerohour” biopsies of renal allograft. Acta Chirr Hung 1997; 36:346-48.

6. Sabnis SG, Antonovych TT, Alijani MR. The value of one hour post-anastomosis biopsy in renal allograft transplantation. Transplantation India 1997; 1: 30-39.

7. Yong Z.Z, Aitken E L, Khan K H et al. Wedge Versus Core Biopsy at Time Zero: Which Provides Better Predictive Value for Delayed Graft Function With the Remuzzi Histological Scoring System? Transplantation Proceedings.2015; 47(6) : 1605 - 09

8. Lee AL, Kim YS, Lim BJ, Jeong HJ. The impact of time-zero biopsy on early graft outcomes after living donor kidney transplantation. Transplant Proc. 2013 ; 45 (8): 2937-40.

9. El-Husseini A, Sabry A, Zahran A et al. Can donor implantation renal biopsy predict long-term renal allograft outcome? Am J Nephrol. 2007; 27 (2): 144-151.

10. Lopes K, Alves R, Neto PA et al. The prognostic value of pre-implantation graft biopsy on the outcomes of renal transplantations. Transplant Proc. 2011; 43 (1): 6769.

11. Verran D, Sheridan A, Barnwell A et al. Biopsy of potential cadaveric renal allografts at the time of retrieval. Nephrology (Carlton). 2005; 10(4):414-17.

12. Naderi GH, Sotoudeh M, Mehraban D and Nategh S. Reliability of Pre-Transplant Live Donor Renal Biopsies in Predicting the Graft Outcome. Int J Organ Transplant Med. 2014; 5: 71-77

13. Kaplan C, Pasternack B, Shah $\mathrm{H}$ et al. Age-related incidence of sclerotic glomeruli in human kidneys. Am J Pathol. 1975; 80(2):227-3

14. Chamienia A, Dębska-Ślizień A, Rutkowski B, et al. 11-year single-center experience in living-donor kidney transplantation in poland. Transplant Proc. 2011; 43:2911-3.

15. Hashikura Y, Kawasaki S. Living donor liver transplantation: issues regarding left liver grafts. HPB (Oxford) 2004; 6: 99-105 
Figures and Tables

Table 1. Effect of various histological changes on graft function at 1 month

\begin{tabular}{|l|l|l|}
\hline $\begin{array}{l}\text { HISTOLOGICAL } \\
\text { CHANGES IN CORTICAL } \\
\text { BIOPSY }\end{array}$ & $\begin{array}{l}\text { NO OF PATIENTS } \\
\text { (OUT OF 84) }\end{array}$ & $\begin{array}{l}\text { EFFECT ON GRAFT } \\
\text { FUNCTION }\end{array}$ \\
\hline NORMAL HISTOLOGY & $48(58 \%)$ & NIL \\
\hline GLOMERULOSCLEROSIS & $21(25 \%)$ & NIL \\
\hline INTERSTITIAL FIBROSIS & $11(13 \%)$ & $\begin{array}{l}\text { DELAYED GRAFT } \\
\text { FUNCTION - } 4\end{array}$ \\
\hline $\begin{array}{l}\text { ACUTE TUBULAR } \\
\text { NECROSIS }\end{array}$ & $4(5 \%)$ & $\begin{array}{l}\text { ACUTE REJECTION- } 2 \\
\text { DELAYED GRAFT } \\
\text { FUNCTION- 2 }\end{array}$ \\
\hline FOCAL TUBAL ATROPHY & $4(5 \%)$ & NIL \\
\hline
\end{tabular}

Table 2. Comparison of serum creatinine in patients with normal histology with that of various coexisting histological changes at $1,3,6$, and 12 months post-surgery

\begin{tabular}{|l|c|c|c|c|c|}
\hline & \multicolumn{5}{|l}{ Mean serum creatinine levels (mg/dl) } \\
\hline & Preop & $\mathbf{1}$ month & $\mathbf{3}$ months & $\mathbf{6}$ months & $\mathbf{1 2}$ months \\
\hline $\begin{array}{l}\text { Normal } \\
\text { histology }\end{array}$ & $0.80 \pm 0.19$ & $0.82 \pm 0.18$ & $0.83 \pm 0.18$ & $0.83 \pm 0.18$ & $0.83 \pm 0.19$ \\
\hline $\begin{array}{l}\text { Glomeruloscl } \\
\text { erosis }\end{array}$ & $0.83 \pm 0.24$ & $0.91 \pm 0.23$ & $0.92 \pm 0.23$ & $1.05 \pm 0.22$ & $0.99 \pm 0.22$ \\
\hline $\begin{array}{l}\text { Interstitial } \\
\text { fibrosis }\end{array}$ & $0.87 \pm 0.24$ & $1.06 \pm 0.22$ & $1.20 \pm 0.21$ & $1.40 \pm 0.24$ & $1.61 \pm 0.28$ \\
\hline $\begin{array}{l}\text { Acute tubal } \\
\text { necrosis }\end{array}$ & $1.05 \pm 0.21$ & $1.15 \pm 0.21$ & $1.15 \pm 0.01$ & $1.25 \pm 0.07$ & $1.30 \pm 0.01$ \\
\hline $\begin{array}{l}\text { Focal tubal } \\
\text { atrophy }\end{array}$ & $0.65 \pm 0.07$ & $0.75 \pm 0.07$ & $0.90 \pm 0.01$ & $1.00 \pm 0.01$ & $1.15 \pm 0.07$ \\
\hline
\end{tabular}




\begin{tabular}{|c|c|c|c|c|c|}
\hline & Preop & 1 month & 3 months & 6 months & 12 months \\
\hline $\begin{array}{l}\text { Normal histology vs. } \\
\text { Glomerulosclerosis }\end{array}$ & 0.8004 & 0.6119 & 0.6192 & 0.7233 & 0.0581 \\
\hline $\begin{array}{l}\text { Normal histology vs. interstitial } \\
\text { fibrosis }\end{array}$ & 0.062 & 0.017 & 0.0024 & 0.0017 & 0.0009 \\
\hline $\begin{array}{l}\text { Normal histology vs. acute } \\
\text { tubal necrosis }\end{array}$ & 0.0742 & 0.002 & 0.0048 & 0.0008 & 0.0003 \\
\hline $\begin{array}{l}\text { Normal histology vs. focal tubal } \\
\text { atrophy }\end{array}$ & 0.2482 & 0.390 & 0.072 & 0.062 & 0.083 \\
\hline
\end{tabular}

\begin{tabular}{|c|c|c|c|c|}
\hline Various studies & $\begin{array}{c}\text { Histological } \\
\text { changes seen }\end{array}$ & $\begin{array}{c}\text { Overall survival } \\
\text { at } 1 \text { year }\end{array}$ & $\begin{array}{c}\text { Allograft } \\
\text { dysfunction }\end{array}$ & $\begin{array}{c}\text { Number of } \\
\text { deaths }\end{array}$ \\
\hline Our study & $\begin{array}{c}\text { GS-25\%, } \\
\text { IF-13\%, ATN-5\%, } \\
\text { FTA-5\% }\end{array}$ & $96 \%$ & $7.4 \%$ & $2(3.8 \%)$ \\
\hline $\begin{array}{l}\text { Naderi et al } \\
(2014)^{12}\end{array}$ & $\begin{array}{c}\text { GS-35\%, IF-16\%, } \\
\text { FTA-6\% }\end{array}$ & $94 \%$ & $9 \%$ & $3(5.5 \%)$ \\
\hline $\begin{array}{l}\text { Kaplan et al } \\
(1975)^{13}\end{array}$ & GS-23\%, IF-6\% & $98 \%$ & $15 \%$ & $1(3 \%)$ \\
\hline $\begin{array}{l}\text { Chamenia et al } \\
(2004)^{14}\end{array}$ & GS-24\%, FTA-15\% & $100 \%$ & $10 \%$ & No deaths \\
\hline $\begin{array}{l}\text { Hashikura et al } \\
(2004)^{15}\end{array}$ & Gs-30\%, HA-6\% & $89 \%$ & $8 \%$ & No deaths \\
\hline
\end{tabular}

